\title{
Optical engineering: understanding optical system by experiments
}

\section{Toralf Scharf}

Toralf Scharf, "Optical engineering: understanding optical system by experiments," Proc. SPIE 10452, 14th Conference on Education and Training in Optics and Photonics: ETOP 2017, 104521F (16 August 2017); doi: $10.1117 / 12.2269114$

SDIE Event: 14th Conference on Education and Training in Optics and Photonics, ETOP 2017, 2017, Hangzhou, China 


\title{
Optical engineering: Understanding optical system by experiments
}

\author{
Toralf Scharf \\ Nanophotonics and Metrology Laboratory, \\ Discovery Learning Laboratory, \\ Ecole Polytechnique Fédérale de Lausanne (EPFL), \\ Lausanne, CH-1015, Switzerland
}

\begin{abstract}
Students have to be educated in theoretical and practical matters. Only one of them does not allow attacking complex problems in research, development, and management. After their study, students should be able to design, construct and analyze technical problems at highest levels of complexity. Who never experienced the difficulty of setting up measurements will not be able to understand, plan and manage such complex tasks in her/his future career. At EPFL a course was developed for bachelor education and is based on three pillars: concrete actions (enactive) to be done by the students, a synthesis of their work by writing a report (considered as the iconic part) and inputs from the teacher to generalize the findings and link it to a possible complete abstract description (symbolic). Intensive tutoring allowed an intermodal transfer between these categories. This EIS method originally introduced by Jerome Bruner for small children is particular well adapted for engineer education for which theoretical understanding often is not enough. The symbiosis of ex-cathedra lecture and practical work in a classroom-like situation presents an innovative step towards integrated learning that complements perfectly more abstract course principles like online courses.
\end{abstract}

Keywords: University education, optical engineering, portable experimental setups

\section{INTRODUCTION}

New trends in teaching such as massive open online courses (MOOCs) often focus on teaching theoretical matter. Such courses are designed for many participants and allow the student learn at his own rhythm. In such teaching formats it is difficult to include high level experiments. In particular in optics classes for bachelor level the equipment needed for experiments is not available in standard household. It therefore clear that a dedicated toolset needs to be provided to keep the level of the matter to teach high. A second aspect is the number of participants. With the trend to homogenize bachelor courses for the first years the class have easily more than 100 participants. Keeping provision for a specialized optics laboratory course by reserving entire laboratory rooms is only economic if the number of participants becomes more than 300. So the optics teaching is often too small to be considered as large class and to big to be carried out in series. We propose here a parallelized course schedule that can be given in series to multiply the number of participants and give some flexibility for the organization. The course material is designed to be nomadic and can travel with the course. The only additional fixed equipment needed is a computer, available in many campus sites in standard computer rooms. Such approach gives flexibility in number if students and also where and when the practical work can be given.

A particular challenging aspect is the matter to teach. The course we discuss here should be accessible to beginners in the field that might have different backgrounds. Our bachelor course is for many students the last contact with optics in an obligatory course before starting specialization. Two aspects had to be considered - allow hands on to "see" and "feel" the optical effects and their specific sensibilities as well as strengthen their fundamental knowledge on system design.

Our strategy is to put at the core of the course several portable setups that support experimental and partially interactive lectures covering all the aspects of optical phenomena, from geometrical optics to interference, speckles passing through spectroscopy and Fourier optics.

*Toralf.Scharf@epfl.ch

14th Conference on Education and Training in Optics and Photonics: ETOP 2017, edited by Xu Liu,

Xi-Cheng Zhang, Proc. of SPIE Vol. 10452, 104521F · ( 2017 ICO, IEEE, OSA, SPIE

CCC code: $0277-786 X / 17 / \$ 18 \cdot$ doi: $10.1117 / 12.2269114$

Proc. of SPIE Vol. $10452104521 \mathrm{~F}-1$ 
The course "Optical engineering" for Microtechnology students is today, after 5 years, the core course of optics education in Bachelor level at EPFL. The course teaches basic of optics and gives the possibility to apply theoretical knowledge to real world problems by doing practical work without leaving the students in dedicated labs. Another strong point, they have contact to the teacher all time. The mix between class room ambiance and practical work frees synergies because all students work on the some subject at the same time and can interact with class mates to search help not only with the teacher and assistants.

\section{OBJECTIVES AND METHODS}

The main objective of "Optical Engineering" is to familiarize the student with basic design and manufacturing problems by realizing miniaturized optical systems. For each lecture, an introduction is followed by experiments and analysis of the results. A modular experimental system was developed that contains basic optical components and serves as experimental kit. The design of the experiments was done to fit into a short time slot of only $3 \mathrm{~h}$. An important aspect is the evaluation of results that starts during the course and has to be finished later as homework. The course is based on using state of the art techniques for analysis of simulation. It introduces not only optics knowledge but in parallel one of the most prominent simulation and analysis tools in industrial research: MATLAB.

The course treats the following subjects:

- Concepts in optics - refraction, diffraction, interference, imaging

- Basic parameters of optical systems (focal length, field of view, signal evaluation)

- Optical components and their characteristics (Sources, monomode and multimode fibers)

- Cameras and imaging (pinhole camera, microcamera and aberrations)

- Advanced optical systems (spectrometer, interferometer, displacement sensor, wavefront sensor)

The course is designed for students without particular pre-knowledge and develops competences for system integration starting from design of optical systems to data evaluation. Students gather practical experience on subjects in optical micro-engineering that is not accessible elsewhere and difficult to teach without "hands-on".
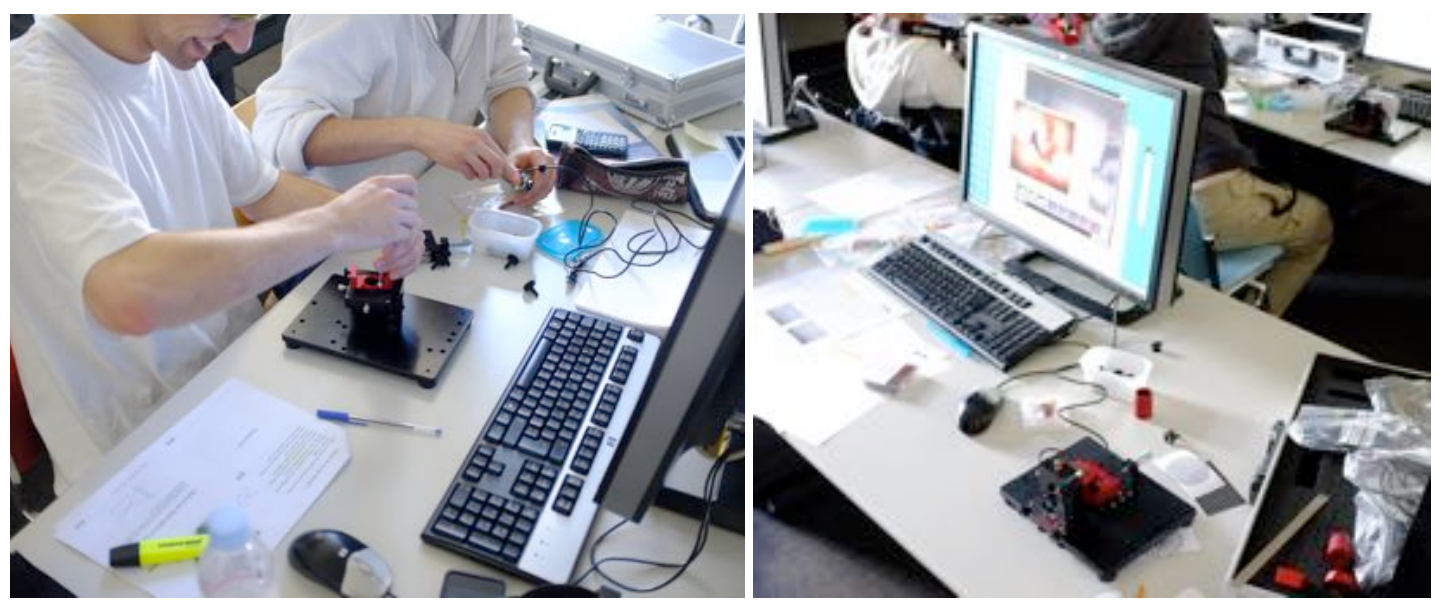

Figure 1. Students at a session mounting and evaluating their experience. (Example: Pinhole camera)

The course is supported by the following elements:

- Full script for 12 experiments and roughly 20 pages (250 pages for the whole script) each containing an objective statement at the beginning, a text book like part explanation of the background and detailed description of work. 
- A newly invented optical toolbox (20 units, allows 40 students maximum per session) that allows to teach different subjects from introducing components to more complicated complete measurement systems and has the potential for extension. The toolbox is mobile and can be also used for demonstration and nomadic experiments also outside a lab or classroom.

- A lecture hall that has a matching number of PCs and analyses software (MATLAB) installed to run the experiment and to do the evaluation.

- The teacher that is present in the classroom all time to give the ex-cathedra lecture (20 min), supervises the work and provide personal feedback for each group (30 groups, 5-10 min feedback for each).

- Two teaching assistants for 15 groups that help with technical matter and supervise the work are present during the course.

Figure 2 shows the content of the optical toolbox. It contains a breadboard and specialized optical components such as lenses, alignment stages etc. In Fig. 3 we show some of the setups that can be mounted with material.

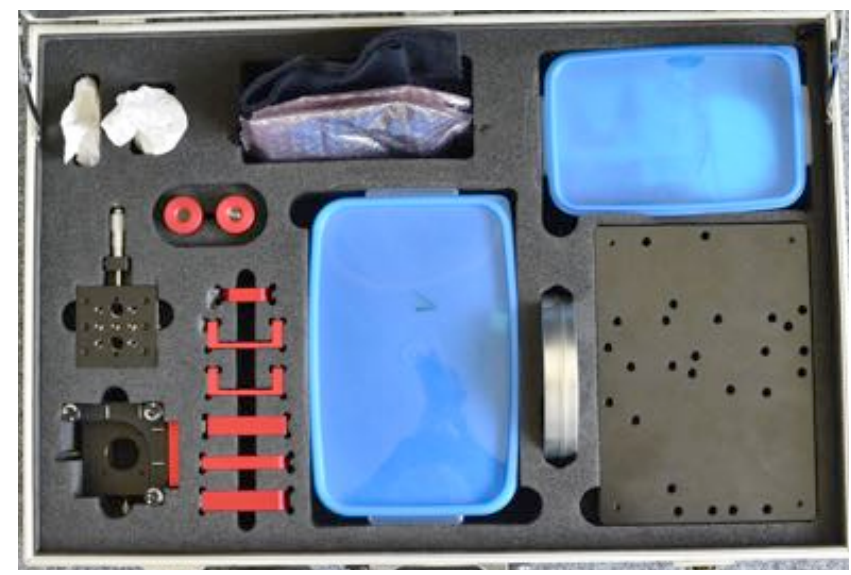

Figure 2. Toolbox developed especially for the lecture. It does not need special equipment expect a PC for running evaluations and experiment. All active components are UBS powered.

A)

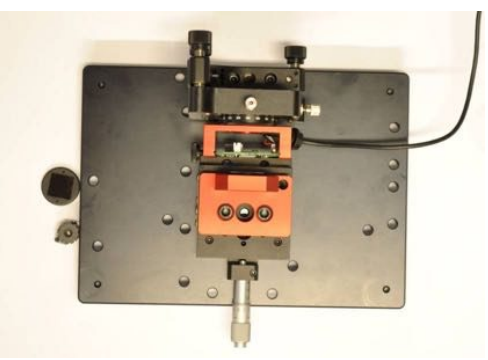

C)

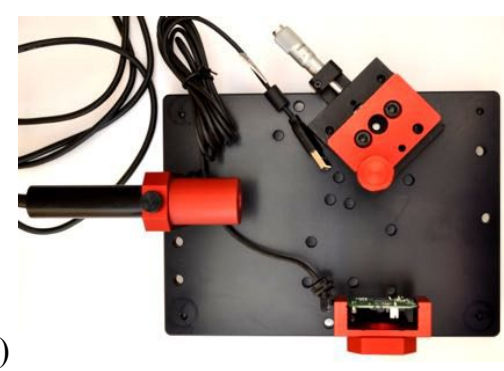

B)

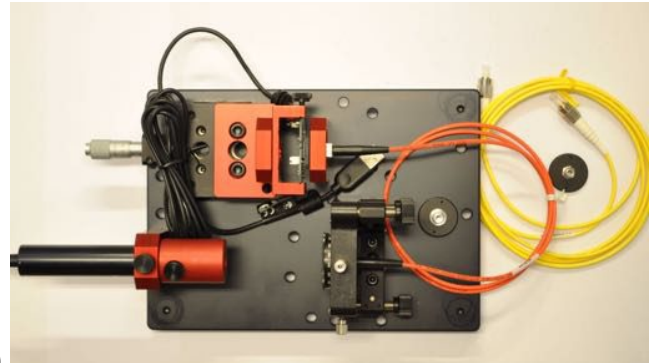

D)

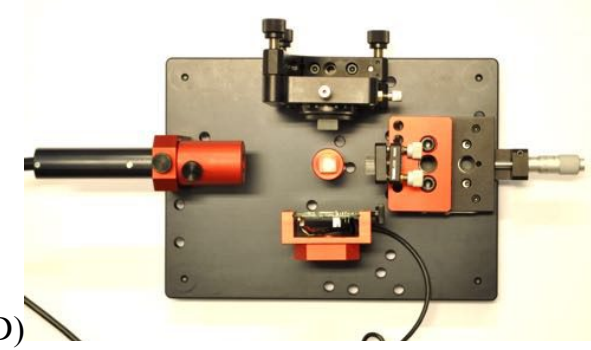

Figure 3: Examples of setups: A) Micro-camera, B) Fiber optics, C) Speckle movement sensor and D) interferometer 
To provide more details of the matter to be teached Table 1 gives a list of subjects linked to each practical work session. A list of key words is added to help the student for exam preparation and identify the most important concepts and parameters. For instance in the session pinhole camera (TP6) the following problems will be discussed:

- Geometrical image construction,

- Geometric and diffraction limited resolution,

- Spatial frequency,

- Contrast and MTF,

- Intensity distribution over the field

A closer looks reveals that here simple concepts like geometrical image construction are repeated in the beginning which should be already known by the students. In a second step new and more complicated concept such as spatial frequency and modulation transfer function MTF are introduced. The idea here of this two level approach is to re-activity the students pre-knowledge first to create confidence for further steps. This is of course not possible for all subjects and has to be managed for each session separately.

Table 1. Table List of exam cards and keywords linked to each laboratory session

\begin{tabular}{|c|}
\hline Imaging (TP1, 10) \\
\hline $\begin{array}{c}\text { Imaging with a thin lens, magnification, } \mathrm{F} \# \text {, numerical aperture, beam collimation, aberrations, resolution limit, } \\
\text { Airy disk }\end{array}$ \\
\hline Detector (TP2) \\
\hline $\begin{array}{l}\text { Parameters: gain and exposure, dynamic range, detection chain and sources of noise, software based image } \\
\text { improvements (brightness, contrast, HDR) }\end{array}$ \\
\hline Sources (TP3) \\
\hline $\begin{array}{c}\text { Operation principles of Halogen-LED-Laser, parameters of sources: size-solid angle-spectrum, focussing of } \\
\text { sources, brightness }\end{array}$ \\
\hline Fibers $(\mathrm{TP} 4,5)$ \\
\hline $\begin{array}{c}\text { Types of fibres: multimode and single-mode, operation principle and modes, parameters: numerical aperture - size, } \\
\text { efficient coupling }\end{array}$ \\
\hline Pinhole camera (TP6) \\
\hline $\begin{array}{l}\text { Geometrical image construction, geometric and diffraction limited resolution, spatial frequency, contrast and } \\
\text { MTF, intensity distribution over the field }\end{array}$ \\
\hline Spectrometer (TP7) \\
\hline $\begin{array}{l}\text { Spectrometer design and main components: grating - slit - optics, grating diffraction, spectral resolution, } \\
\text { calibration procedures: spectral and amplitude }\end{array}$ \\
\hline Interferometer (TP8) \\
\hline $\begin{array}{l}\text { Origin of interference, Michelson interferometer, coherence length, two wavelengths interference and beat } \\
\text { frequency, phase shifting technique }\end{array}$ \\
\hline Speckles (TP9) \\
\hline $\begin{array}{l}\text { Origin of speckles, parameters determining the speckle size, correlation of images, spatial noise, limitations of } \\
\text { motion detection with speckles }\end{array}$ \\
\hline Diffraction (TP11) \\
\hline $\begin{array}{l}\text { Diffraction patterns after apertures (slit, circle, square, arbitrary), grating equation, parameters dependence of the } \\
\text { diffraction pattern of a binary grating - period - slit width }\end{array}$ \\
\hline
\end{tabular}




\section{TEACHING FOCUS, ASSESSMENT AND EXAM PROCEDURE}

Doing practical work often leads to the question what skills are acquired except only screwing components together. In optics, practical experience is particularly important because optics uses macroscopic components with $\mathrm{cm}$ size to achieve nanometer precision and is the leading tool for measurement and qualification in research and industry nowadays. The advantage in optics is that results of a measurement can directly be seen. It allows therefore for direct feedback and active control of the desired measurement outcome.

In the due course of the first year of lecturing this course having 50 students in class it become evident that the concept of mixing ex-cathedra and practical work gets very demanding and the focus need to be put on the practical work. Excathedra lectures were reduced to a maximum of 20 min duration each session and provide only a short introduction and examples before each practical session. At the same time a personal feedback with each group (usually 15 groups of two students per session, 5-10 min feedback per group) was introduced with overwhelming success. This serves two objectives: control the acquired learning outcomes and skills and learn from the students how to improve and optimize this teaching method.

To consolidate the knowledge, hand written protocols have to be delivered each week, are corrected and serve as discussion material for the feedback. An example of the laboratory notebook used for this task is shown in Fig. 4. The lab-notebook concept is used to introduce the student to a continuous reporting that can start already in the class. Doing so and interacting with the teaching assistants and the teacher creates confidence and helps to prevent from deviation. One particular risk when using reports that are based on word processing based reports is fraud. Hand written reports are much less subjected to such problems and the handwriting also helps to revise the matter and think arguments carefully through before write it down. A simple copy paste from external sources and the web makes just no sense under such conditions.

An oral exam after the lecture together with the necessary review of matter by the students helps to check on improvement in student skill level and monitors the progress of the students. There are four main objectives of the lecture (learning outcome). The student should be able to:

- Explain the contents of each experience and document it in a report (examination by evaluating the report)

- Use a state of the art tool for evaluation of results (MATLAB) to visualise, document and analyse the outcomes of the work (examination by evaluating the report)

- Capable of finding and defining the most important characteristics of optical components (examination in the feedback discussions and in the oral exam)

- Understand the main design principles and limitations of optical systems (examination in the feedback discussions and in the oral exam)

Because there are no exercises in the conventional sense students often ask what will be the subject of the oral exam (duration 15-20 min). Therefore particular care needs to be taken to state the technical objectives for exam preparation. Two measures are introduced: an extensive list of self control questions is made available and the method of exam cards (Table 1) is used that state key words for the student to be examined and can be used in the oral exam as a support for a first round of questions. A second series of question with a subject chosen by the teacher and depending on the performance allows for broader evaluation.

\section{INNOVATIVE ASPECTS OF TEACHING}

Students have to be educated in theoretical and practical matters. Only one of them does not allow attacking complex problems in research, development, and management. After their study, students should be able to design, construct and analyze technical problems at highest levels of complexity. Who never experienced the difficulty of setting up measurements will not be able to understand, plan and manage such complex tasks in her/his future career.

The course was given to beginners in the field that might have different backgrounds. Two aspects had to be considered - strengthen their fundamental knowledge on system design and allow hands on to "see" and "feel" the optical effects and their specific sensibilities.

We introduced here the method of EIS developed by Brunner [1] for pre-school education and adapted for university teaching. The course was based on concrete actions (enactive) to be done by the students, a synthesis of their work by 
writing a report (considered as the iconic part) and inputs from the teacher to generalize the findings and link it to a possible complete abstract description (symbolic). Intensive tutoring allowed an intermodal transfer between these categories. This EIS method originally introduced by Jerome Bruner for small children is particular well adapted for engineer education for which theoretical understanding often is not enough. The symbiosis of ex cathedra lecture and practical work in a classroom-like situation presents an innovative step towards integrated learning that complements perfectly more abstract course principles like online courses as promoted at EPFL via MOOCs.

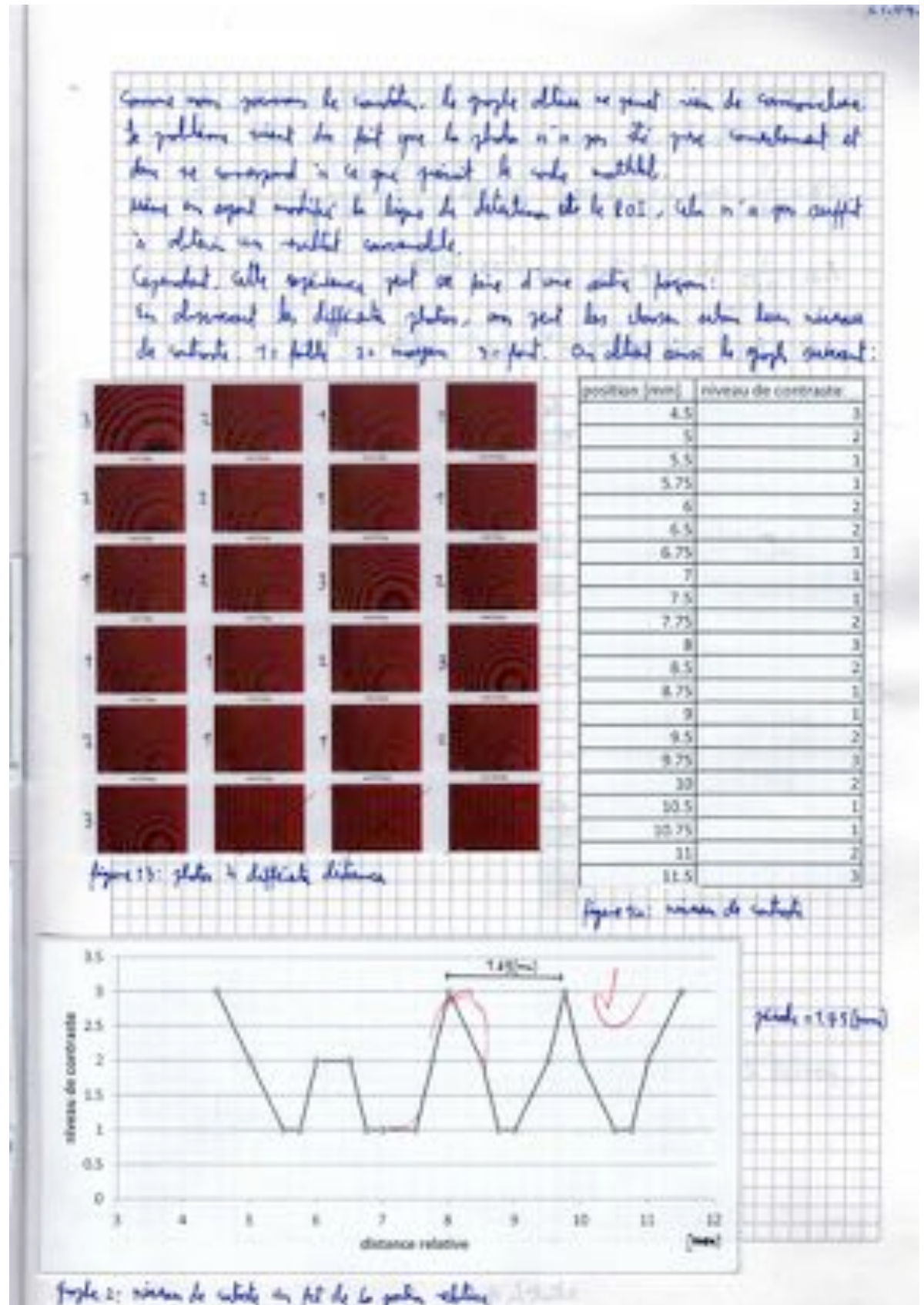

Figure 4: Sample page of the report to be delivered by the group of students. Here results of the session "interferometer" are discussed. The mix of photos, graphs and discussion help to synthetize problems and deepens the understaning of the work done. 


\section{ACKNOWLEDGEMENTS}

The teaching activity was supported by EPFL internal funds of the Microtechnology section and is now part of the Discovery Learning Laboratory DLL at EPFL. The concept used in this lecture was honored by an invitation to give one lecture cycle at the Abbe School of Photonics in Jena/Germany and got awarded with an "InnoLecture-Gastdozentur" by the German foundations Carl-Zeiss-Stiftung and Stifterverband in 2011/2012. The author received the Credit Suisse "Best Lecturer Award" for EPFL teachers in 2016.

This research has received funding from the European Union's Horizon 2020 research and innovation program under the Marie Skłodowska-Curie Grant Agreement No. 675745.

\section{REFERENCES}

[1] Bruner, J. S. (1966). Toward a theory of instruction, Cambridge, Mass.: Belkapp Press. 